\title{
Buccal patches of atenolol formulated using fenugreek (Trigonella foenum-graecum L.) seed mucilage
}

\author{
Surya Narayan Ratha Adhikari ${ }^{A-E}$, Satyabrata Panda ${ }^{C, E, F}$ \\ Department of Pharmaceutics, Seemanta Institute of Pharmaceutical Sciences, Mayurbhanj, Odisha, India \\ A - research concept and design; $\mathrm{B}$ - collection and/or assembly of data; $\mathrm{C}$ - data analysis and interpretation; \\ $D$ - writing the article; $E$ - critical revision of the article; $F$ - final approval of article
}

Address for correspondence

Surya Narayan Ratha Adhikari

E-mail: snarayan.rath@rediffmail.com

\section{Funding sources}

none declared

Conflict of interest

none declared

\section{Acknowledgements}

The authors are grateful to Dr. Amit Kumar Nayak, Department of Pharmaceutics, Seemanta Institute of Pharmaceutical

Sciences, Mayurbhanj, Odisha, India.

Received on February 7, 2016

Revised on February 24, 2016

Accepted on April 18, 2017

\begin{abstract}
Background. The use of mucoadhesive natural polymers in designing mucoadhesive patch systems has received much attention.
\end{abstract}

Objectives. The study involved the development and evaluation of buccal patches of atenolol using fenugreek (Trigonella foenum-graecum L.) seed mucilage with hydroxylpropyl methyl cellulose (HPMC K4M) and a backing membrane (ethyl cellulose 5\% w/v).

Material and methods. These atenolol-releasing buccal patches were prepared using a solvent casting technique. The buccal patches prepared were evaluated for average weight, thickness, drug content, folding endurance and moisture content. Ex vivo mucoadhesive strength, force of adhesion and bonding strength were determined using porcine buccal mucosa. The mucosal permeation of atenolol through the porcine buccal mucosa was carried out using a Franz diffusion cell in phosphate buffer saline, pH 6.8. These buccal patches were also characterized by SEM and FTIR spectroscopy.

Results. The average weight, thickness, drug content, folding endurance and moisture content of these atenolol-releasing buccal patches were found satisfactory for all the patches. Amongst all, the F-4 buccal patch showed maximum mucoadhesive strength $(31.12 \pm 1.86 \mathrm{~g})$, force of adhesion $\left(30.53 \times 10^{-2} \mathrm{~N}\right)$ and bond strength $\left(1748.89 \mathrm{~N} / \mathrm{m}^{2}\right)$. Ex vivo atenolol permeation from the buccal patches showed drug permeation across the excised porcine buccal mucosa over $12 \mathrm{~h}$. The $\mathrm{F}-4$ buccal patch showed maximum permeation flux $\left(29.12 \mu \mathrm{g} / \mathrm{cm}^{2} / \mathrm{h}\right)$

Conclusions. The developed atenolol-releasing buccal patches can be beneficial over the conventional drug delivery systems to decrease the dosing frequency and enhance patient compliance.

Key words: fenugreek seed mucilage, HPMC, mucoadhesion, buccal patches, atenolol

DOI

10.17219/pim/70498

Copyright

(C) 2017 by Wroclaw Medical University

This is an article distributed under the terms of the

Creative Commons Attribution Non-Commercial License

(http://creativecommons.org/licenses/by-nc-nd/4.0/) 
During last few decades, a lot of research work has been done in buccal drug delivery systems. ${ }^{1-3}$ Delivery of drugs via the buccal mucosa to the systemic circulation is defined as buccal drug delivery. ${ }^{4}$ Though less permeable than the sublingual area, the buccal mucosa is well vascularized and drugs can be rapidly absorbed into the systemic circulation underneath the oral mucosa. ${ }^{5}$ The mucosa of the buccal area has a large, smooth and relatively immobile surface, which provides a larger contact surface. The large contact surface of the buccal mucosa contributes to rapid and extensive drug absorption. ${ }^{6}$ In recent years, buccal drug delivery has proven particularly useful and offers several advantages over other drug deliveries including: bypass of the gastrointestinal tract and hepatic portal systems, increasing the bioavailability of orally administered drugs that otherwise undergo hepatic firstpass metabolism, improved patient compliance due to the elimination of associated pain with injections, administration of drugs to unconscious patients, sustained drug delivery, increased ease of drug administrations and ready termination of delivery by detaching the dosage form. ${ }^{7}$ In current years, several buccal patches of different drugs have been researched by various research groups ${ }^{8-11}$ Buccal patches are modified-release dosage forms composed of a thin matrix composed of one or more polymers, drugs and other excipients. In the previous literature, a few attempts have been undertaken to design atenolol-releasing buccal films and patches..$^{9,12-15}$ However, in the previous literature, no attempt has been undertaken to formulate atenolol patches using plant-derived natural mucoadhesive polymers along with hydroxylpropyl methyl cellulose (HPMC). HPMC is a release-retardant polymer. Therefore, it was thought to provide delayed release of atenolol from these buccal patches for a longer period.

The present research work involves the formulation and development of atenolol (an anti-hypertensive drug) releasing buccal patches made of fenugreek (Trigonella foenum-graecum L.) seed mucilage (a plant-derived mucoadhesive biopolymer) and HPMC so that the various preparations obtained sustained a prolonged drug release profile with suitable mucoadhesive properties. Fenugreek seed mucilage is a galactomannan and stable polymer. ${ }^{16}$ It consists of a $(1 \rightarrow 4) \beta$-D-mannan backbone to which single $\alpha$-D-galactopyranosyl groups are attached at the O-6 position of D-mannopyranosyl residues with $\mathrm{D}$-galactose and D-mannose ratio, $1: 1$ or $1: 1.2 .{ }^{16,17}$ The present study

Table 1. Composition of different buccal patches containing atenolol

\begin{tabular}{|l|c|c|c|c|}
\multicolumn{1}{c|}{ Formula } & F-1 & F-2 & F-3 & F-4 \\
\hline Atenolol (mg) & 50 & 50 & 50 & 50 \\
HPMC K4M (mg) & 500 & 400 & 300 & 200 \\
Fenugreek seed mucilage (mg) & 500 & 600 & 700 & 800 \\
Glycerin (\% w/w) & 15 & 15 & 15 & 15 \\
Sodium saccharin (\% w/v) & 0.1 & 0.1 & 0.1 & 0.1 \\
Distilled water (mL) & 40 & 40 & 40 & 40 \\
\hline
\end{tabular}

focuses on the formulation and evaluation of atenolol-releasing buccal patches made of a mucoadhesive polymeric layer of fenugreek seed mucilage-HPMC and a drug-free backing membrane consisting of $1 \% \mathrm{w} / \mathrm{v}$ ethyl cellulose. The $1 \% \mathrm{w} / \mathrm{v}$ ethyl cellulose was used as backing layer.

\section{Material and methods}

\section{Material}

Atenolol was obtained from M/S. P.D.I.L, India. HPMC K4M and ethyl cellulose were obtained from Matrix Laboratories, India. Glycerin was purchased from Loba Chemie Pvt. Ltd., India. Sodium saccharin was purchased from Reidel India Chemicals, India. Fenugreek (Trigonella foenum-graecum L.) seed mucilage was isolated from the raw fenugreek seeds. The procedure of fenugreek seed mucilage extraction has been described in previously published literature by Nayak et al. ${ }^{16,17}$ The chemicals used were of analytical grade and double-distilled water was used throughout.

\section{Preparation of buccal patches of atenolol}

The buccal patches consisting of mucoadhesive polymeric layers of fenugreek seed mucilage-HPMC containing atenolol $(50 \mathrm{mg})$ and sodium saccharin $(0.1 \% \mathrm{w} / \mathrm{v})$ were prepared by a solvent casting technique. The mixture solutions of atenolol, mucoadhesive polymers (fenugreek seed mucilage and HPMC), and sodium saccharin were well mixed using a magnetic stirrer (Remi Motors, India) at $100 \mathrm{rpm}$ for $15 \mathrm{~min}$ and then, homogenized using a homogenizer stirrer (Remi Motors, India) for $15 \mathrm{~min}$. Glycerin was used as a plasticizer within the mixture solution at a concentration of $15 \% \mathrm{w} / \mathrm{w}$ of dry weight of the polymers. The solutions were then sonicated again for $30 \mathrm{~min}$ to remove air bubbles. The sonicated solutions were poured in petri dishes of $54 \mathrm{~cm}^{2}$ area and were dried at $50^{\circ} \mathrm{C}$ for $24 \mathrm{~h}$. The drug-free backing layer was prepared onto the drug containing mucoadhesive polymeric layers by using $1 \% \mathrm{w} / \mathrm{v}$ ethyl cellulose solution in ethyl alcohol by a solvent casting technique and the prepared bilayered patches were dried at $50^{\circ} \mathrm{C}$ for $5 \mathrm{~h}$. Then, the dried atenolol patches were obtained from the petri dishes, cut into circular pieces of $1 \mathrm{~cm}^{2}$ and appropriately preserved. Table 1 shows the composition of different buccal patches containing atenolol.

\section{Measurement of average weight and thickness}

The average weights of all the patches were calculated including the measurement of their thickness at 6 different points using thickness gauze (Mitutoyo, Japan). For each formulation, 3 randomly-selected patches were used. ${ }^{9}$ 


\section{Determination of drug content}

The drug content uniformity in the formulated buccal patches were determined by weighing 6 patches $\left(1 \mathrm{~cm}^{2}\right)$ dissolved in $100 \mathrm{~mL}$ isotonic phosphate buffer ( $\mathrm{pH}$ 6.8) and shaken vigorously for $24 \mathrm{~h}$ at room temperature. Then the resulting solution was filtered, diluted and analyzed for DS content spectrophotometrically using a UVVIS spectrophotometer (UV-1700 Double beam spectrophotometer, SHIMADZU Corporation, Japan) at $274 \mathrm{~nm}$ against a blank. The drug content was estimated from the calibration curve, which was constructed between 1 and $5 \mu \mathrm{g} / \mathrm{mL}$ concentration ranges. The method was validated for linearity, accuracy, and precision. The regression equation for the calibration curve was $\mathrm{Y}=0.048 \mathrm{X}+0.002$, $\mathrm{R} 2=0.9990$.

\section{Measurement of folding endurance}

The folding endure without breakage of the patches was determined by repeatedly folding one patch at the same place till it broke or folded up to 300 times at the same place without break. The number of times the buccal patches could be folded at the same place without breaking or cracking gave the value of folding endurance. ${ }^{18}$

\section{Determination of moisture content}

The buccal patches were weighed accurately and kept in desiccators containing anhydrous calcium chloride. After 3 days, the patches were taken out and weighed. ${ }^{19}$ The moisture content (\%) was determined by calculating moisture loss (\%) using the formula:

$$
\begin{gathered}
\text { initial weight }- \text { final weight } \\
\text { moisture content }(\%)=\times 100 \\
\text { initial weight }
\end{gathered}
$$

\section{Ex vivo studies}

\section{Preparation of goat buccal mucosa}

The goat buccal mucosa excised from a goat cheek pouch was obtained within $2 \mathrm{~h}$ of its death from the slaughter house and kept immediately in phosphate buffer solution. The buccal mucosa was isolated from the full thickness of the tissue and finally washed with phosphate buffer saline, $\mathrm{pH} 6.8$.

\section{Ex vivo mucoadhesion study}

The mucoadhesive parameters (mucoadhesive strength, force of adhesion and bonding strength) of all the fabricated buccal patches were measured ex vivo $(n=3)$ by a modified physical balance using excised porcine buccal mucosa as described by Gupta et al. ${ }^{20}$ A piece of excised porcine buccal mucosa was tied to the open mouth of a glass vial filled completely with phosphate buffer saline, $\mathrm{pH}$ 6.8. The glass vial was tightly fitted in the center of a beaker filled with phosphate buffer saline ( $\mathrm{pH}$ 6.8; temperature, $37 \pm 1^{\circ} \mathrm{C}$ ). The patches were stuck to the lower side of the rubber stopper with glue. The mass (in g) required to detach the patches from the mucosal surface gave the measure of mucoadhesive strength (shear stress). The following parameters were calculated from mucoadhesive strength: ${ }^{10}$

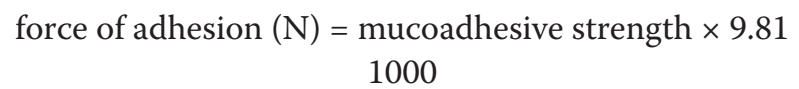

bonding strength $\left(\mathrm{N} / \mathrm{m}^{2}\right)=$ force of adhesion surface area of mucosal surface

\section{Ex vivo permeability study}

The formulated buccal patches that were evaluated for the permeation of atenolol through the porcine buccal mucosa were carried out using a Franz diffusion cell. The effective diffusion area was $1.74 \mathrm{~cm}^{2}$. The receptor compartment $(40 \mathrm{~mL})$ was filled with phosphate buffer saline, $\mathrm{pH} 6.8$, and its temperature was maintained at $37 \pm 1^{\circ} \mathrm{C}$. The buccal cavity environment was stimulated by applying a magnetic stirrer $(100 \mathrm{rpm})$. The patch was applied under occlusion on the buccal mucosal surface fitted between the donor and receptor compartments of the diffusion cell. Five milliliters of the sample from the receptor medium was withdrawn at predetermined time intervals and an equal volume of pre-warmed phosphate buffer saline $\mathrm{pH} 6.8$ was replaced immediately. The amount of atenolol released into the receptor compartment was quantified by using a UV-VIS spectrophotometer (UV-1700 double beam spectrophotometer, SHIMADZU Corporation, Japan) at $274 \mathrm{~nm}$ against a blank.

\section{Ex vivo permeation data analysis}

Permeation flux: The amount of atenolol from the various buccal patches permeated through the excised porcine buccal mucosa was plotted against the function of time. The slope and intercept of the linear portion of the plots were derived by regression. The permeation fluxes for each patch were calculated as the slope divided by the mucosal surface area: ${ }^{14}$

$$
\mathrm{J}_{\mathrm{ss}}=(\mathrm{dQ} / \mathrm{dt})_{\mathrm{ss}} \cdot 1 / \mathrm{A}
$$

where $J_{s s}$ is the steady-state permeation flux $\left(\mu \mathrm{g} / \mathrm{cm}^{2} / \mathrm{h}\right)$, $\mathrm{A}$ is the area of buccal mucosa $\left(\mathrm{cm}^{2}\right)$ through which drug permeation takes place, and $(\mathrm{dQ} / \mathrm{dt})_{\mathrm{ss}}$ is the amount of drug passing through the buccal mucosa per unit time at a steady state $(\mu \mathrm{g} / \mathrm{h})$. 
Table 2. Average weight, thickness, drug content, folding endurance and moisture content of atenolol-containing buccal patches

\begin{tabular}{|c|c|c|c|c|}
\hline Formula & $\mathrm{F}-1$ & $\mathrm{~F}-2$ & $\mathrm{~F}-3$ & $\mathrm{~F}-4$ \\
\hline Average weight $(\mathrm{g})^{\mathrm{a}}$ & $2.07 \pm 0.08$ & $2.17 \pm 0.09$ & $2.08 \pm 0.07$ & $2.09 \pm 0.07$ \\
\hline Thickness $(\mathrm{mm})^{\mathrm{b}}$ & $0.58 \pm 0.06$ & $0.60 \pm 0.04$ & $0.57 \pm 0.06$ & $0.58 \pm 0.05$ \\
\hline Drug content $(\%)^{b}$ & $99.48 \pm 2.78$ & $99.02 \pm 2.57$ & $98.37 \pm 2.68$ & $98.66 \pm 2.43$ \\
\hline Folding endurance & 88 & 83 & 82 & 80 \\
\hline Moisture content $(\%)^{b}$ & $1.21 \pm 0.09$ & $1.22 \pm 0.07$ & $1.36 \pm 0.09$ & $1.50 \pm 0.12$ \\
\hline
\end{tabular}

a mean \pm standard deviation, $n=6$.

${ }^{\mathrm{b}}$ mean \pm standard deviation, $\mathrm{n}=3$.

Permeation kinetics: The data of ex vivo atenolol permeation from the various buccal patches through excised porcine buccal mucosa were evaluated kinetically using various mathematical models like zero order, first order, Higuchi, and Korsmeyer-Peppas model equations. ${ }^{21}$

Zero order model: $\mathrm{F}=\mathrm{K}_{0} \mathrm{t}$, where $\mathrm{F}$ represents the fraction of the drug permeated in time $t$ and $K_{0}$ is the zero order rate constant.

First order model: $\ln (1-F)=-K_{1} t$, where F represents the fraction of the drug permeated in time $t$ and $K_{1}$ is the first-order rate constant.

Higuchi model: $\mathrm{F}=\mathrm{K}_{\mathrm{H}} \mathrm{t}^{1 / 2}$, where $\mathrm{F}$ represents the fraction of the drug permeated in time $\mathrm{t}$ and $\mathrm{KH}$ is the Higuchi rate constant.

Korsmeyer-Peppas model: $F=K_{p} t^{n}$, where F represents the fraction of the drug permeated in time " $t$ " and $K_{p}$ is the Korsmeyer-Peppas rate constant, and " $n$ " is the diffusion exponent.

Again, the Korsmeyer-Peppas model was employed in the ex vivo atenolol permeation behavior analysis of these formulations to find out permeation mechanisms: Fickian (non-steady) when $\mathrm{n} \leq 0.5$, case-II transport (zero order) when $\mathrm{n} \geq 1$, and non-Fickian (anomalous) when the value of $\mathrm{n}$ is in between 0.5 and $1 .{ }^{22}$

\section{Analysis of surface morphology}

The surface morphology of these patches was examined by scanning electron microscopy (SEM). The dried patches were coated with gold sputter and then observed under scanning electron microscope (JEOL, JSM 840, Japan).

\section{Analysis of drug-polymer compatibility}

The drug-polymer compatibility of the prepared patches was analyzed by Fourier transform-infrared (FTIR) spectroscopy. Pure drug (atenolol) and atenolol-containing buccal patches were scanned over a wave number range of 3600 to $600 \mathrm{~cm}^{-1}$ at a resolution of $4 \mathrm{~cm}^{-1}$ using a FTIR spectrophotometer (BRUKER). The system was operated in transmission mode.

\section{Statistical analysis}

All data was analyzed with simple statistics. The simple statistical analysis was conducted using MedCalc software v 11.6.1.0.

\section{Results and discussion}

The main aim of the research work was to formulate and evaluate atenolol-(an anti-hypertensive drug) releasing buccal patches containing the drug in a mucoadhesive polymeric layer of fenugreek seed mucilage-HPMC and a drug-free backing membrane composed of $1 \% \mathrm{w} / \mathrm{v}$ ethyl cellulose using the solvent casting technique.

\section{Average weight and thickness}

The average weights and thicknesses of these atenololcontaining buccal patches as a whole $\left(54 \mathrm{~cm}^{2}\right)$ were measured within the range, $2.07 \pm 0.08$ to $2.17 \pm 0.09 \mathrm{~g}$ and $0.57 \pm 0.06$ to $0.60 \pm 0.04 \mathrm{~mm}$, respectively (Table 2 ).

\section{Drug content}

The uniformity of drug contents in $1 \mathrm{~cm}^{2}$ of each buccal patch were determined. The drug contents in all these buccal patches varied between the range $98.37 \pm 2.68$ and $99.48 \pm 2.78 \%$ (Table 2). This shows that the drug dispersed uniformly throughout the drug-containing polymeric layer.

\section{Folding endurance}

The folding endurances of these formulated buccal patches were measured manually. The highest folding endurance was observed in the case of F-1 (18) and the lowest in the case of F-4 (10) (Table 2). It was observed that the folding endurances of the patches were found to be decreased with the decrease of fenugreek seed mucilage within the formula of these patches. The folding endurance study signifies flexibility of the designed buccal patches.

\section{Moisture content}

The percentages of moisture content (\%) of all these atenolol-containing buccal patches were measured within the range $1.21 \pm 0.09$ to $1.50 \pm 0.12 \%$ (Table 2 ). The low moisture content protects it from microbial contamination, reduces the bulkiness of the formulated patches and gives it stability from brittleness. ${ }^{14}$ 
Table 3. Mucoadhesive parameters (ex vivo mucoadhesive strength, force of adhesion and bonding strength) of atenolol-containing buccal patches

\begin{tabular}{|l|c|c|c|}
\multicolumn{1}{|c|}{ Formulations } & F-1 & F-2 & F-3 \\
\hline Mucoadhesive strength in $(\mathrm{g})^{\mathrm{a}}$ & $21.48 \pm 1.36$ & $23.12 \pm 1.27$ & $26.82 \pm 1.44$ \\
Force of adhesion $(\mathrm{N})^{\mathrm{a}}$ & $21.07 \times 10-2$ & $22.68 \times 10-2$ & $26.31 \times 10-2$ \\
Bonding strength $\left(\mathrm{N} / \mathrm{m}^{2}\right)^{\mathrm{a}}$ & 1211.03 & 1303.49 & $30.53 \times 10-2$ \\
\hline
\end{tabular}

${ }^{\text {a }}$ mean \pm standard deviation, $\mathrm{n}=3$.

\section{Ex vivo mucoadhesion}

The mucoadhesion of buccal patches may be defined as the adhesion between the buccal patches and buccal mucosa. The strength of the mucoadhesion is affected by various factors such as the biological membrane used in the study, molecular mass, and the swelling rate of the polymers present in the formulation. ${ }^{13}$ In this investigation, freshly excised porcine buccal mucosa was used as the biological membrane. Various mucoadhesive parameters like ex vivo mucoadhesive strength (in gram), force of adhesion $(\mathrm{N})$ and bonding strength $\left(\mathrm{N} / \mathrm{m}^{2}\right)$ were measured by a modified physical balance using excised goat buccal mucosa as described by Gupta et al. ${ }^{20}$ The results of the ex vivo mucoadhesion study of atenolol-containing buccal patches using excised porcine buccal mucosa are presented in Table 3. Among all these formulated patches, the F-4 atenolol-containing buccal patch showed maximum mucoadhesive strength $(31.12 \pm 1.86 \mathrm{~g})$, force of adhesion $\left(30.53 \times 10^{-2} \mathrm{~N}\right)$, and bond strength $\left(1748.89 \mathrm{~N} / \mathrm{m}^{2}\right)$. It was observed that the mucoadhesion of these patches was found to be increased with the increment of fenugreek seed mucilage incorporation in the buccal patch formula as the mucoadhesive polymer. The ex vivo mucoadhesive strengths, forces of adhesion and bonding strengths of these newly-formulated atenolol-containing buccal patches were found satisfactory for mucoadhesion in the oral cavity with the buccal mucosal surface.

\section{Ex vivo permeation}

The ex vivo permeation of atenolol from the various buccal patches showed that the drug easily permeates through

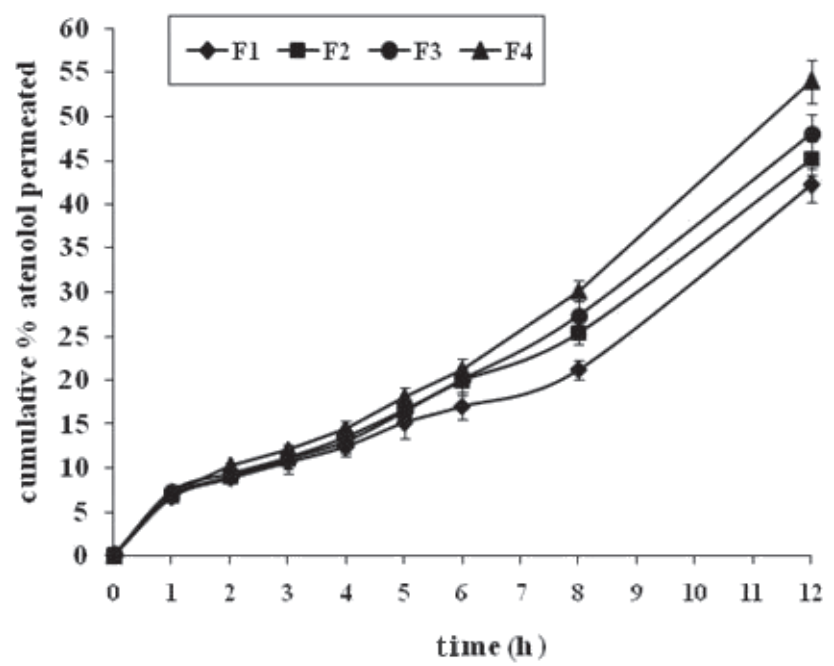

Fig. 1. Ex vivo atenolol permeation from the various atenolol-containing buccal patches the excised goat buccal mucosa during a period of $12 \mathrm{~h}$ and is shown in Fig. 1. It was further found that the maximum ex vivo drug permeation was $50.36 \pm 2.43 \%$ over a period of 12 hours in the case of the F-4 atenolol-containing buccal patch, while the minimum ex vivo drug permeation was found to be $42.17 \pm 1.88 \%$ over a period of in the case of the F-1 atenolol-containing buccal patch. The permeation fluxes $\left(\mathrm{J}, \mu \mathrm{g} / \mathrm{cm}^{2} / \mathrm{h}\right)$ were calculated for each buccal patch and are presented in Table 4 . The permeation flux results showed the maximum permeation flux $\left(29.12 \mu \mathrm{g} / \mathrm{cm}^{2} / \mathrm{h}\right)$ for the $\mathrm{F}-4$ atenolol-containing buccal patch, compared to that of the others.

To discover the permeation of atenolol from different buccal formulations, it is necessary to fit it into a suitable mathematical model. The ex vivo atenolol permeation data from buccal patches across the excised porcine buccal mucosa were evaluated kinetically using various mathematical models like zero order, first order, Higuchi, and KorsmeyerPeppas model equations. ${ }^{21}$ The results of the curve fitting of the ex vivo atenolol permeation data into these abovementioned mathematical models indicate the atenolol permeation behavior from these formulated buccal patches of atenolol across the excised porcine buccal mucosa (Table 5). The ex vivo atenolol permeations were found to follow the first order model $\left(\mathrm{R}^{2}=0.9858\right.$ to 0.9943$)$ over a period of $12 \mathrm{~h}$ of permeation across the excised porcine buccal mucosa. The values determined for the diffusion exponent (n) of the prepared atenolol-containing buccal patches ranged between 0.69 and 0.76 (Table 5) indicating a non-Fickian (anomalous) diffusion mechanism of drug permeation. The anomalous diffusion mechanism describes both diffusioncontrolled, and swelling-controlled drug permeation. ${ }^{24}$

Table 4. Permeation flux $\left(\mathrm{J}, \mu \mathrm{g} / \mathrm{cm}^{2} / \mathrm{h}\right)$ results for the various atenolol-containing buccal patches

\begin{tabular}{|c|c|}
\hline Formulations & Permeation flux $\left(\mathrm{J}, \mu \mathrm{g} / \mathrm{cm}^{2} / \mathrm{h}\right)$ \\
\hline $\mathrm{F}-1$ & 24.87 \\
\hline $\mathrm{F}-2$ & 25.03 \\
\hline$F-3$ & 27.28 \\
\hline$F-4$ & 29.12 \\
\hline
\end{tabular}

Table 5. Results of the curve fitting of the ex vivo permeation data of the various atenolol-containing buccal patches

\begin{tabular}{|l|c|c|c|c|}
\multicolumn{1}{|c|}{ Formulation code } & F1 & F2 & F3 & F4 \\
\hline Zero order model & 0.9375 & 0.9637 & 0.9638 & 0.9552 \\
First order model & 0.9881 & 0.9858 & 0.9913 & 0.9943 \\
Higuchi model & 0.6457 & 0.6385 & 0.6361 & 0.6099 \\
Korsmeyer-Peppas model & 0.9134 & 0.9308 & 0.9161 & 0.9072 \\
$\mathrm{n}$ (diffusion exponent) & 0.69 & 0.72 & 0.74 & 0.76 \\
\hline
\end{tabular}




\section{Surface morphology}

An SEM microphotograph of the F-4 atenolol-containing buccal patch is shown in Fig. 2. It shows a nearly smooth surface with the presence of very few drug particles. This indicated good lamination of the polymers within the patch, where the drug particles were homogeneously dispersed throughout the patch matrix. The presence of drug particles on the surface of the patch matrix might be a result of their migration along with water to the patch surface during drying.

\section{Drug-polymer compatibility}

The drug-polymer compatibility of the prepared buccal patches was analyzed by FTIR spectroscopy. The FTIR spectra of fenugreek seed mucilage, HPMC $\mathrm{K} 4 \mathrm{M}$, ethyl cellulose, the F-4 atenolol-containing buccal patch and the pure drug (atenolol) are presented in Fig. 3. The FTIR spectrum of pure atenolol showed various characteristic peaks of atenolol like at 3305 and $1416 \mathrm{~cm}^{1}$ due to $-\mathrm{O}-\mathrm{H}$, at $1337 \mathrm{~cm}^{1}$ due to $-\mathrm{CH} 3$, and at 1036 and $1242 \mathrm{~cm}^{1}$ due to $-\mathrm{N}-\mathrm{C}$, as expected. ${ }^{25}$ All these characteristic peaks of pure atenolol appeared in the spectra of the F-4 atenolol-containing buccal patch without or with very minute shifting, indicating that there was an absence of any chemical interaction between the drug (here atenolol) and the excipients used. The intensity of the peaks of pure atenolol was diminished due to the molecular dispersion of the atenolol in the polymer matrix of the buccal patch.

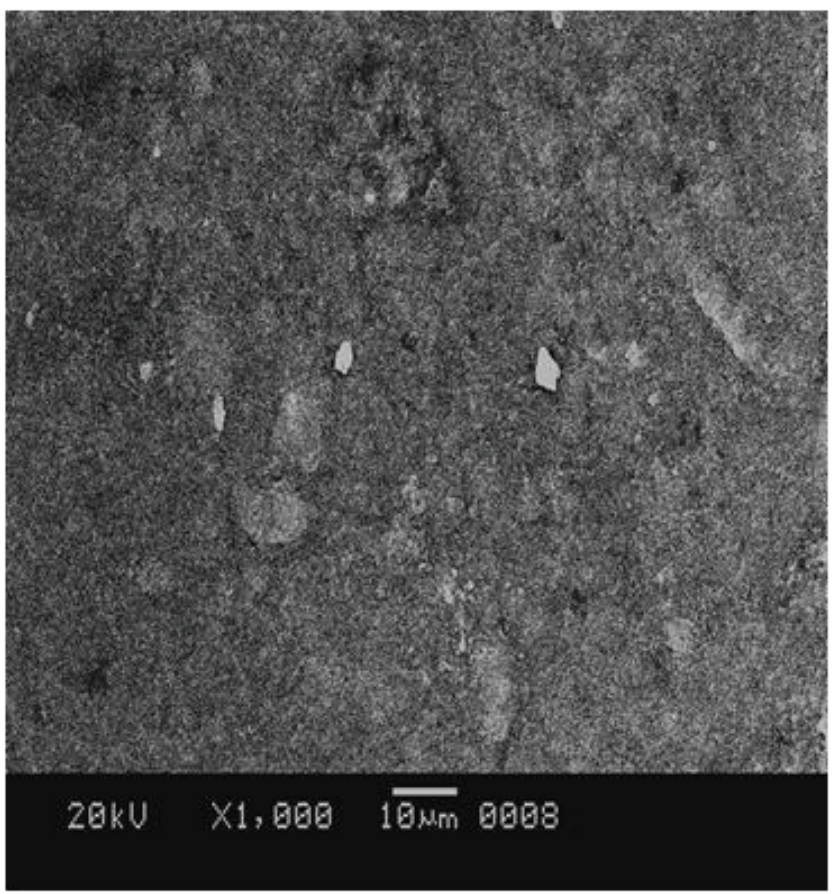

Fig. 2. SEM microphotograph of the F-4 atenolol-containing buccal patch

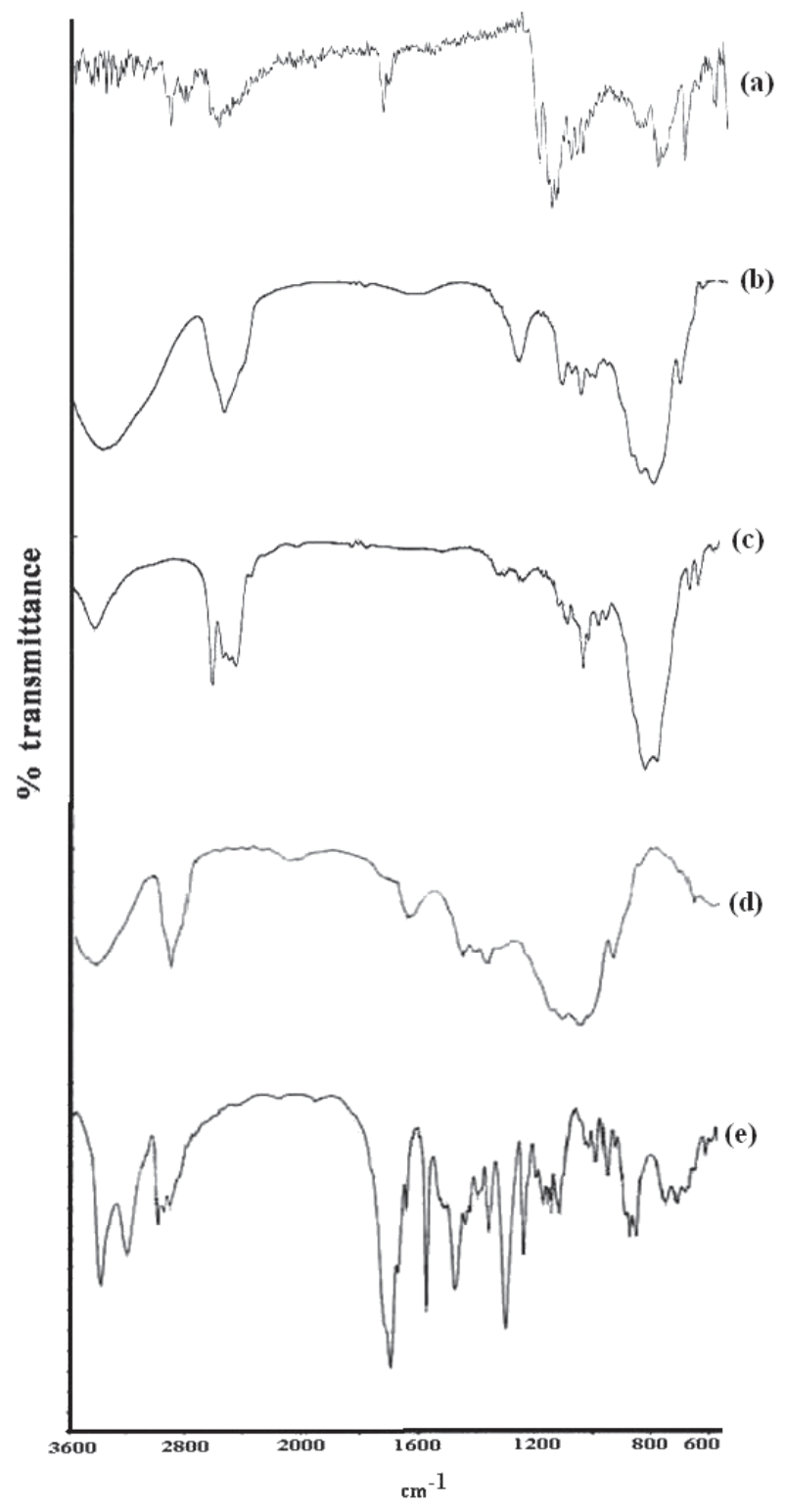

Fig. 3. The FTIR spectra of fenugreek seed mucilage (a), HPMC K4M (b), ethyl cellulose (c), the F-4 atenolol-containing buccal patch (d) and the pure drug (atenolol)

\section{Conclusion}

From the present work, it can be concluded that in such mucoadhesive buccal patches of atenolol made of a mucoadhesive polymeric layer of fenugreek seed mucilage-HPMC and a drug-free backing membrane composed of $1 \% \mathrm{w} / \mathrm{v}$ ethyl cellulose using a solvent casting technique, $1 \% \mathrm{w} / \mathrm{v}$ ethyl cellulose was found suitable to provide a sustained buccal delivery of atenolol for prolonged periods in the management of hypertension, which can be a good way to bypass the extensive hepatic first-pass metabolism. In the future, the in vivo ability of these newly-developed atenololreleasing buccal patches will be investigated. 


\section{References}

1. Hao H, Heng PWS. Buccal drug delivery systems. Drug Dev Ind Pharm. 2003;29:821-832.

2. Avachat AM, Gujar KN. Development and evaluation of tamarind seed xyloglucan-based mucoadhesive buccal films of rizatriptan benzoate. Carbohydr Polym. 2013;91:537-542.

3. Koland M, Charyulu RN, Prabhu P. Mucoadhesive films of losartan potassium for buccal delivery: Design and characterization. Indian J Pharm Educ Res. 2010;44:315-323.

4. Boylan JC. Drug delivery buccal route. In: J. Swarbrick (ed.), Encyclopedia of Pharmaceutical Technology. Suppl. 3, Marcel Dekker Inc 2001, 800-811.

5. De Vries ME, Bodde HE, Verhoef JC, Junginger HE. Developments in buccal drug delivery. Crit Rev Ther Drug Carrier Syst. 1991;8:271-303.

6. Shojaei $A H$. Buccal mucosa as a route for systemic drug delivery. Review. J Pharm Pharmaceut Sci. 1998;1:15-30.

7. Smart JD. Buccal drug delivery. Exp Opin Drug Deliv. 2005;2:507-517.

8. Shiledar RR, Tagalpallewar AA, Kokare CR. Formulation and in vitro evaluation of xanthan gum-based bilayered mucoadhesive buccal patches of zolmitriptan. Carbohydr Polym. 2014;101:1234-1242.

9. Verma N, Wahi AK, Verma A, Chattopadhayay P. Evaluation of mucoadhesive buccal patches for delivery of atenolol. J Pure Appl Microbiol. 2007;1:115-118.

10. Patel VM, Prajapati BG, Patel MM. Design and characterization of chitosan- containing mucoadhesive buccal patches of propranolol hydrochloride. Act Pharm. 2007;57:61-72.

11. Pongjanyakul $T$, Suksri $H$. Alginate-magnesium aluminum silicate films for buccal delivery of nicotine. Colloids Surf B Biointerf. 2009;74:103-113.

12. Jug $M$, Bećirević-Laćan $M$, Bengez $S$. Novel cyclodextrin-based film formulation intended for buccal delivery of atenolol. Drug Dev Ind Pharm. 2009;35:796-807.

13. Krishnarth $\mathrm{N}$, Verma N, Sharma N. Formulation \& evaluation of muccoadhesive buccal patches for delivery of atenolol. Int J Pharm. 2014:4:166-170.

14. Ratha Adhikari SN, Nayak BS, Nayak AK, Mohanty B. Formulation and evaluation of buccal patches for delivery of atenolol. AAPS PharmSciTech. 2010;11:1038-1044.

15. Satishbabu BK, Srinivasan BP. Preparation and evaluation of buccoadhesive films of atenolol. Indian J Pharm Sci. 2008;70:175-179.

16. Nayak AK, Pal D, Pradhan J, Ghorai T. The potential of Trigonella foenum-graecum $L$. seed mucilage as suspending agent. Indian J Pharm Educ Res. 2012;46:312-317.

17. Nayak AK, Pal D, Pradhan J, Hasnain MS. Fenugreek seed mucilagealginate mucoadhesive beads of metformin $\mathrm{HCl}$ : Design, optimization and evaluation. Int J Biol Macromol. 2013;54:144-154.

18. Nafee NA, Ahemed F, Borale A. Preparation and evaluation of mucoadhesive patches for delivery of cetylpyridinium chloride (CPC). Acta Pharm. 2003;2:199-212.

19. Attama AA, Akpa PA, Onugwa LE, Igwilo G. Novel buccoadhesive delivery system of hydrochlorothiazide formulated with ethyl cellulose-hydroxypropyl methylcellulose interpolymer complex. Sci Res Essays. 2008;3:343-347.

20. Gupta A, Garg S, Khar RK. Measurement of bioadhesion strength of muco-adhesive buccal tablet: Design of an in vitro assembly. Indian Drugs. 1992;30:152-155.

21. Malakar J, Sen SO, Nayak AK, Sen KK. Formulation, optimization and evaluation of transferosomal gel for transdermal insulin delivery. Saudi Pharm J. 2012;20:355-363.

22. Malakar J, Sen SO, Nayak AK, Sen KK. Development and evaluation of microemulsions for transdermal delivery of insulin. ISRN Pharmaceutics. 2011 (2011) Article ID 780150.

23. Park H, Robinson JR. Mechanism of bioadhesion of poly (acrylic acid) hydrogels. Pharm Res. 1987;4:457-464.

24. Das B, Nayak AK, Nanda U. Topical gels of lidocaine $\mathrm{HCl}$ using cashew gum and Carbopol 940: Preparation and in vitro skin permeation. Int J Biol Macromol. 2013;62:514-517.

25. Cozar O, Chis V, David L, Baias M. Experimental and density functional theory investigation of some biomedical compounds. J Optoelectronics Adv Mater. 2006;8:164-171. 